Journal of Zoo and Wildlife Medicine 31(4): 484-490, 2000

Copyright 2000 by American Association of Zoo Veterinarians

\title{
HEMATOLOGY AND SERUM BIOCHEMISTRY PARAMETERS OF NORTH AMERICAN RIVER OTTERS (LONTRA CANADENSIS)
}

\author{
Maryanne E. Tocidlowski, D.V.M., Lucy H. Spelman, D.V.M., Perry W. Sumner, M.S., and \\ Michael K. Stoskopf, D.V.M., Ph.D.
}

\begin{abstract}
Blood samples were obtained from 155 North American river otters (Lontra canadensis; 94 adult males, 38 adult females, 10 juvenile males, and 13 juvenile females) to establish baseline hematology and from 50 adult river otters (40 males and 10 females) for baseline serum biochemistry parameters for the species. The otters were livetrapped from eastern North Carolina (USA) during a 4-yr period. Data for 14 routine hematologic parameters and 22 serum chemistry assays showed significant differences in total leukocyte count and absolute neutrophil and monocyte numbers for adults versus juveniles, red blood cell counts and hemoglobin between adult and juvenile males, and calcium and alkaline phosphatase values for adult males between years of the study and an increase in leukocyte counts and absolute neutrophils with increased degree of trap injury sustained.
\end{abstract}

Key words: Biochemistry, clinical pathology, hematology, Lontra canadensis, mustelid, river otter, trap injury.

\section{INTRODUCTION}

Translocated wildlife may transmit diseases into new locations, reducing translocation success rate and influencing native wildlife populations. ${ }^{4}$ Animals scheduled for translocation should have medical evaluations that include a physical examination, clinical pathology assessment, and disease screening, and any clinical illness or wound should be managed. ${ }^{13}$ Clinical pathology baseline values help define population health and nutritional status and aid in the identification of infectious or noninfectious diseases. These values may change with season, ${ }^{11}$ nutritional state, ${ }^{1}$ reproductive status, and capture method. ${ }^{19}$ Previous studies of river otter clinical pathology have been small in scale and were conducted under a variety of environmental and husbandry conditions., , $5-7,9,12^{0}$

This study established baseline hematology for 155 livetrapped North American river otters (Lontra canadensis; 94 adult males, 38 adult females, 10 juvenile males, and 13 juvenile females) during each December-February between 1991 and 1994 and 1995 and 1996 and baseline serum chemistry parameters from 50 of the adults (40 males and 10 females) from the same population during the same

From the Environmental Medicine Consortium and Department of Clinical Sciences, North Carolina State University, College of Veterinary Medicine, 4700 Hillsborough Street, Raleigh, North Carolina 27606, USA (Tocidlowski, Spelman, Stoskopf); the North Carolina Wildlife Resources Commission, 512 North Salisbury Street, Archdale Building, Raleigh, North Carolina 27604, USA (Sumner). Present addresses: Houston Zoological Gardens, 1513 North MacGregor Street, Houston, Texas 77030, USA (Tocidlowski); and the Department of Animal Health, National Zoological Park, 3001 Connecticut Avenue, NW, Washington, D.C. 20008, USA (Spelman). months in the two study years of 1991-1992 and 1995-1996.

\section{MATERIALS AND METHODS}

\section{Animals and husbandry}

The otters were livetrapped for the North Carolina Wildlife Resources Commission Otter Restoration/Translocation Project (Raleigh, North Carolina, USA) by wildlife biologists and cooperating local trappers with various sized standard and modified leghold traps in compliance with recommendations by the Commission's Institutional Animal Care and Use Committee. The animals originated from 10 North Carolina counties.

Otters were housed alone or in groups of two in $0.5-\times 1.0-\times 0.5-\mathrm{m}$, vinyl-coated welded wire cages kept in a covered open air shelter. They were fed a variety of fresh or frozen fish twice daily with drinking water provided ad lib. All otters received a 10-day course of trimethoprim sulfadiazine (DiTrim, Syntex Animal Health, West Des Moines, Iowa 50265, USA; $30 \mathrm{mg} / \mathrm{kg}$ p.o. s.i.d.) in fish once they started to eat, usually within 3 days after arrival. The otters were physically examined and had blood and fecal samples collected and wounds treated between 4 and 26 days (median 7 days) after retrieval from the trap and arrival at the holding facility (time of capture).

All of the otters sustained trap injuries to one limb, either minor lacerations (12\%, including puncture wounds, missing claws, swelling of the paw), closed luxations of one or more digits (32\%), open or compound luxations of one or more digits (41\%), or open luxations with exposure or fracture of bones of the digits (15\%). Wounds were treated conservatively by cleaning with dilute betadine solution, debridement, and minor suturing where appropriate. 


\section{Anesthesia}

The otters were fasted for $12 \mathrm{hr}$ prior to anesthesia. They were weighed and injected with i.m. agents by regimes as previously published. ${ }^{14-18}$ Anesthetized animals were placed in dorsal recumbency, and the rectal temperature, heart rate, respiration rate, and pulse oximetry measurements were monitored.

\section{Cohort inclusion}

The individuals studied were selected from 293 translocated otters on the basis of successful release, acclimation of a minimum of 4 days from time of capture to sampling, lack of pregnancy (in females, on the basis of palpation), absence of canine or molar tooth fractures that exposed the root pulp, and the absence of any clinical sign of illness such as respiratory distress, lethargy, abscesses, purulent discharges, abnormal swellings, or dehydration. Animals were categorized subjectively as adult $(>1 \mathrm{yr})$ or juvenile ( $\leq 1 \mathrm{yr}$ ) on the basis of body size, tooth size, tooth wear. Adults weighed 4-11 kg (median $8 \mathrm{~kg}$ ) and juveniles weighed 4-8 $\mathrm{kg}$ (median $6 \mathrm{~kg}$ ). The teeth of juveniles were generally smaller than those of adults, unstained, and sharply pointed with little wear. The teeth of adults were dulled from wear, often stained and chipped, broken, or worn at the tips. Gender was determined by palpation of a baculum in males or by observation of external genitalia.

\section{Specimen handling and analysis}

Blood (10-12 ml) was taken from the jugular vein of anesthetized otters with a 12-ml syringe and 20-ga needle and placed into EDTA tubes and serum separator vacutainer tubes (Vacutainer ${ }^{\circledR}$, Becton Dickson, Franklin Lakes, New Jersey 07417 , USA). Two blood smears were made from each EDTA tube shortly after collection, and the tube was chilled and analyzed within 6-10 hr. Smears were air dried, stored 6-10 hr, and stained. The serum separator tube was allowed to clot for $30 \mathrm{~min}$, then centrifuged for $10 \mathrm{~min}$. The serum was decanted, divided into three aliquots in cryocontainers, placed on ice for transport, frozen at $-70^{\circ} \mathrm{C}$, and analyzed within $6 \mathrm{wk}$ of collection.

Complete blood counts (Table 1), including WBCs, erythrocyte counts, $\mathrm{Hgb}$, Hct, $\mathrm{MCV}, \mathrm{MCH}$, and $\mathrm{MCHC}$ determinations, and platelet counts were obtained for all otters with automated cell counters ( $\mathrm{S}+\mathrm{IV}$, Coulter Electronics, Inc., Hialeah, Florida 33010, USA during 1992; System 9000 Serono-Baker Diagnostics, Inc., Allentown, Pennsylvania 18103, USA during 1993-1996). Both analyzers directly count leukocytes, erythrocytes, he-
Table 1. Number of North American river otter blood specimens used to establish hematology and biochemistry (in parentheses) baseline parameters.

\begin{tabular}{|c|c|c|c|c|c|}
\hline \multirow[b]{2}{*}{ Year } & \multicolumn{2}{|c|}{ Adult } & \multicolumn{2}{|c|}{ Juvenile } & \multirow{2}{*}{$\begin{array}{c}\text { Total } \\
\text { number }\end{array}$} \\
\hline & Male & Female & Male & Female & \\
\hline 1992 & $20(20)$ & $1(1)$ & 1 & 0 & $22(21)$ \\
\hline 1993 & 21 & 19 & 0 & 2 & 42 \\
\hline 1994 & 29 & 6 & 0 & 1 & 36 \\
\hline 1996 & $24(20)$ & $12(9)$ & 9 & 10 & $55(29)$ \\
\hline All & $94(40)$ & $38(10)$ & 10 & 13 & $155(50)$ \\
\hline
\end{tabular}

moglobin, mean corpuscular volume, and platelet parameters. Because of inconsistent instrument calibration for platelets in 1994, only values from the years 1992, 1993, and 1996 were used to determine platelet parameters. Hematocrit, $\mathrm{MCH}$, and $\mathrm{MCHC}$ values were arithmetically derived from the directly measured parameters.

One blood smear per otter was stained with a Romanowsky type stain (Leucostat ${ }^{\text {WW }}$, Fisher Scientific, Pittsburgh, Pennsylvania 15219, USA) and scanned with $\times 100$ light microscopy for overall quality and the presence of microfilaria. Differential counts were conducted by examining 200 leukocytes under $\times 1,000$ (oil immersion) or $\times 400$ magnification. Cell morphology was studied at $\times 1,000$. Absolute leukocyte values for each otter were determined by multiplying the percentage of each leukocyte cell type found in the differential cell count by the total WBC obtained from the automated analyzer.

Sera were submitted from 50 of the adult (40 male and 10 female) otters for biochemical analysis in $1992(n=21)$ and $1996(n=29)$ (Table 1$)$. Frozen sera were sent in 1992 to North Carolina State University Veterinary Teaching Hospital, Clinical Pathology Laboratory (Raleigh, North Carolina 27606, USA) and analyzed with a Monarch Plus ${ }^{\circledR}$ automatic analyzer (Instrumentation Laboratory, Lexington, Massachusetts 02173, USA). Frozen samples in 1996 were sent to LabCorp (Burlington, North Carolina 27215, USA) and analyzed with an Olympus AU5200 automatic analyzer (Olympus America, Inc., Lake Success, New York 11042, USA). Each sample was analyzed for concentrations of calcium, phosphorus, sodium, potassium, chloride, ALT, AST, Alk P, T. Bili, CPK, total protein, albumin, BUN, creatinine, and glucose. Total globulin concentration was calculated by subtracting the total albumin value from the total protein value. During 1992, the total $\mathrm{CO}_{2}, \mathrm{LDH}$, and amylase concentrations were obtained, whereas 
Table 2. Hematology and serum biochemistry values for adult live-trapped river otters (Lontra canadensis).

\begin{tabular}{|c|c|c|c|c|c|c|}
\hline \multirow[b]{2}{*}{ Parameter } & \multirow[b]{2}{*}{ Units } & \multicolumn{5}{|c|}{ Adults } \\
\hline & & $n$ & Median & $2.5 \%^{\mathrm{a}}$ & $97.5 \%^{\mathrm{a}}$ & Range \\
\hline WBC & $\times 10^{3} / \mu 1$ & 132 & 11.3 & 5.0 & 25.2 & $4.7-33.2$ \\
\hline $\mathrm{RBC}$ & $\times 10^{3} / \mu 1$ & 132 & 10.99 & 8.49 & 13.33 & $6.10-14.50$ \\
\hline $\mathrm{Hgb}$ & $\mathrm{g} / \mathrm{dl}$ & 132 & 15.1 & 11.8 & 17.8 & $10.4-19.0$ \\
\hline Hct & $\%$ & 132 & 47.6 & 35.6 & 58.1 & $32.2-60.8$ \\
\hline $\mathrm{MCV}$ & $\mathrm{fl}$ & 132 & 43.3 & 39.8 & 48.2 & $38.3-49.0$ \\
\hline $\mathrm{MCH}$ & pg & 132 & 13.7 & 12.0 & 15.1 & $11.3-15.8$ \\
\hline $\mathrm{MCHC}$ & $\mathrm{g} / \mathrm{dl}$ & 132 & 31.4 & 28.2 & 35.9 & $27.8-39.2$ \\
\hline Plt & $\times 10^{3} / \mu 1$ & 132 & 565 & 321 & 838 & $298-931$ \\
\hline Neutrophils & $\mu l$ & 132 & 8,879 & 3,338 & 23,168 & $3,003-28,220$ \\
\hline Bands & $\mu 1$ & 132 & 94 & 47 & 423 & $0-486$ \\
\hline Lymphocytes & $\mu 1$ & 132 & 1,254 & 300 & 4,225 & $123-4,950$ \\
\hline Monocytes & $\mu 1$ & 132 & 452 & 102 & 2,041 & $52-2,380$ \\
\hline Eosinophils & $\mu 1$ & 132 & 312 & 43 & 1,530 & $0-1,833$ \\
\hline Basophils & $\mu 1$ & 132 & 88 & 65 & 203 & $0-219$ \\
\hline $\mathrm{Ca}$ & $\mathrm{mg} / \mathrm{dl}$ & 50 & 8.4 & 7.2 & 9.6 & $6.8-10.0$ \\
\hline Phos & $\mathrm{mg} / \mathrm{dl}$ & 50 & 5.8 & 3.8 & 7.8 & $3.2-8.3$ \\
\hline $\mathrm{Na}$ & $\mathrm{mEq} / \mathrm{L}$ & 50 & 152 & 138 & 158 & $136-158$ \\
\hline K & $\mathrm{mEq} / \mathrm{L}$ & 50 & 4.4 & 3.8 & 5.3 & $3.5-5.3$ \\
\hline $\mathrm{Cl}$ & $\mathrm{mEq} / \mathrm{L}$ & 50 & 113 & 104 & 120 & $94-121$ \\
\hline $\mathrm{TCO}_{2}$ & $\mathrm{mEq} / \mathrm{L}$ & 21 & 24 & 19 & 28 & $19-28$ \\
\hline ALT & IU/L & 50 & 194 & 56 & 566 & $46-990$ \\
\hline AST & IU/L & 50 & 85 & 45 & 871 & $34-1,260$ \\
\hline Alk Phos & IU/L & 50 & 85 & 35 & 213 & $29-282$ \\
\hline T. Bili & $\mathrm{mg} / \mathrm{dl}$ & 50 & 0.2 & 0.1 & 0.4 & $0.1-0.5$ \\
\hline Chol & $\mathrm{mg} / \mathrm{dl}$ & 29 & 152 & 69 & 237 & $63-279$ \\
\hline Trig & $\mathrm{mg} / \mathrm{dl}$ & 29 & 31 & 10 & 71 & $9-72$ \\
\hline GGT & IU/L & 29 & 19 & 9 & 32 & $8-38$ \\
\hline CPK & IU/L & 50 & 219 & 85 & 803 & $67-1,300$ \\
\hline LDH & IU/L & 21 & 149 & 45 & 7,570 & $36-10,820$ \\
\hline T. Prot & $\mathrm{g} / \mathrm{dl}$ & 50 & 7.3 & 5.9 & 8.5 & $5.7-9.0$ \\
\hline Glob & $\mathrm{g} / \mathrm{dl}$ & 50 & 4.0 & 2.9 & 5.3 & $2.9-5.8$ \\
\hline Alb & $\mathrm{g} / \mathrm{dl}$ & 50 & 3.3 & 2.7 & 3.8 & $2.4-4.1$ \\
\hline BUN & $\mathrm{mg} / \mathrm{dl}$ & 50 & 31 & 19 & 48 & $17-56$ \\
\hline Creat & $\mathrm{mg} / \mathrm{dl}$ & 50 & 0.5 & 0.4 & 0.8 & $0.4-0.8$ \\
\hline Glu & $\mathrm{mg} / \mathrm{dl}$ & 50 & 130 & 98 & 196 & $56-225$ \\
\hline Amy & IU/L & 21 & 12 & 3 & 19 & $2-22$ \\
\hline
\end{tabular}

a Percentiles.

cholesterol, triglyceride, and GGT concentrations were measured in 1996.

\section{Statistical analysis}

Statistical analysis was conducted on data groups containing more than nine data points after the data were examined for normal distribution. ${ }^{3}$ Age, gender, year of capture, days held to sampling, and degree of injury groups were compared. The Wilcoxon rank sums test was used when two sets of data were compared and the Kruskal-Wallis rank sums test when there were multiple data sets. If significant differences were found in the KruskalWallis rank sums test, the data groups were further characterized with the Tukey-Kramer comparisons for all pairs. Statistical significance was set at $P \leq$ 0.05 , and computations were done with a computer software package (JMP ${ }^{\circledR}$, SAS Institute Inc., Cary, North Carolina 27513, USA).

\section{RESULTS}

Clinical pathology values with median, 2.5th, and 97.5th percentiles and ranges from adult and juvenile eastern North Carolina river otters during the $4 \mathrm{yr}$ of study are presented in Tables 2 and 3 . Clinical pathology values for adult males and females were summarized together because no statistically significant differences with apparent clinical 
Table 3. Hematology values for juvenile live-trapped river otters (Lontra canadensis).

\begin{tabular}{llccccc}
\hline & & \multicolumn{5}{c}{ Juveniles } \\
\cline { 3 - 6 } \multicolumn{1}{c}{ Parameter } & \multicolumn{1}{c}{$n$ Units } & $n$ & Median & $2.5 \%^{\mathrm{a}}$ & $97.5 \%^{\mathrm{a}}$ & Range \\
\hline WBC & $\times 10^{3} / \mu \mathrm{l}$ & 23 & 7.1 & 3.5 & 12.8 & $3.2-13.1$ \\
$\mathrm{RBC}$ & $\times 10^{3} / \mu \mathrm{l}$ & 23 & 10.11 & 7.73 & 12.81 & $7.46-13.67$ \\
$\mathrm{Hgb}$ & $\mathrm{g} / \mathrm{dl}$ & 23 & 13.5 & 11.7 & 17.2 & $11.4-17.9$ \\
$\mathrm{Hct}$ & $\%$ & 23 & 43.4 & 35.9 & 54.1 & $35.1-57.6$ \\
$\mathrm{MCV}$ & $\mathrm{fl}$ & 23 & 42.8 & 40.8 & 47.4 & $40.6-48.9$ \\
$\mathrm{MCH}$ & $\mathrm{pg}$ & 23 & 13.8 & 13.0 & 15.3 & $12.9-16.0$ \\
MCHC & $\mathrm{g} / \mathrm{dl}$ & 23 & 32.0 & 29.6 & 35.0 & $28.4-36.2$ \\
Plt & $\times 10^{3} / \mu \mathrm{l}$ & 23 & 561 & 397 & 785 & $394-834$ \\
Neutrophils & $\mu \mathrm{l}$ & 23 & 5,084 & 1,874 & 10,539 & $1,778-10,962$ \\
Bands & $\mu \mathrm{l}$ & 23 & 62 & 34 & 220 & $0-232$ \\
Lymphocytes & $\mu \mathrm{l}$ & 23 & 1,183 & 630 & 2,835 & $441-3,200$ \\
Monocytes & $\mu \mathrm{l}$ & 23 & 224 & 40 & 953 & $28-963$ \\
Eosinophils & $\mu \mathrm{l}$ & 23 & 205 & 33 & 882 & $0-1,092$ \\
Basophils & $\mu \mathrm{l}$ & 23 & 58 & 52 & 63 & $0-63$ \\
\hline
\end{tabular}

a Percentiles.

significance were identified between the groups. Slight range differences between hematology values of adults and juveniles dictated that those data be examined independently.

Total leukocyte counts and absolute numbers of neutrophils and monocytes were statistically different between adults and juveniles in 1996 (Tables 2, 3). Statistically significant differences in the serum $\mathrm{Ca}$ and Alk $\mathrm{P}$ were identified between adult males sampled in 1992 and 1996 (respectively) for calcium (8.2/9.0 g/dl) and Alk P (55/109 IU/L). Also, for adult males, red blood cell and Hgb values (respectively) were statistically different between all years of the study: $1992\left(10.40 \times 10^{6} / \mu 1,15.7 \mathrm{~g} /\right.$ dl), $1993\left(11.98 \times 10^{6} / \mu 1,15.6 \mathrm{~g} / \mathrm{dl}\right), 1994(11.16$ $\times 10 \% / \mu \mathrm{l}, 15.5 \mathrm{~g} / \mathrm{dl}), 1996\left(10.51 \times 10^{6} / \mu \mathrm{l}, 14.5 \mathrm{~g} /\right.$ dl).

Leukocytes and erythrocytes of river otters resembled those of other mammals. Occasional (up to three) reactive lymphocytes identified by increased size, basophilic coloration, and slightly less clumped nuclear chromatin than normal lymphocytes were noted on some slides and were included in the lymphocyte category in the leukocyte differential. Nucleated erythrocytes were rare, were not included in any parameter counts, and did not correlate with erythrocyte or leukocyte concentration.

Microfilaria, most closely resembling Dirofilaria lutrae, ${ }^{10}$ could be seen under $\times 100$ magnification in $18.1 \%$ of all blood smears examined. The percentage of blood smears containing microfilaria varied between years with $31.8 \%$ positive smears in $1992,4.8 \%$ in $1993,13.9 \%$ in 1994 , and $25.5 \%$ in 1996. In otters with microfilaria, median MCVs were slightly lower (42.7 fl), median absolute lymphocyte counts were one-half the concentration $(759 / \mu \mathrm{l})$, and median concentrations of sodium (149 mEq/L) and chloride (110 mEq/L) were lower than for otters without microfilaria (MCV $43.4 \mathrm{fl}$,

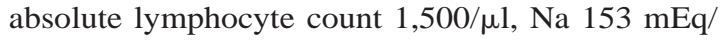
$\mathrm{L}, \mathrm{Cl} 113 \mathrm{mEq} / \mathrm{L}$ ).

Otters were held a median of 7 days prior to sampling (4-26 days). There were no significant differences in the mean number of days held between age, gender, or capture year. A comparison of LDH and WBC with the number of days an animal was held showed no correlation. Serum CPK concentrations $(n=48)$ were inversely correlated with the number of days an otter was held prior to sampling (Fig. 1).

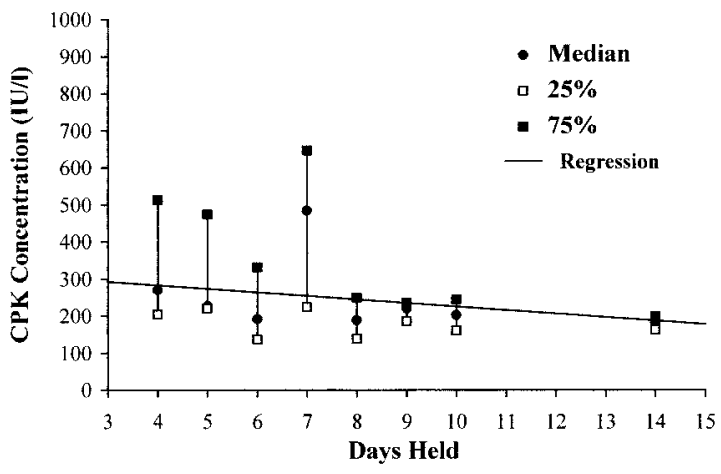

Figure 1. Calculated median (-) (25\% quartile, $\square$; $75 \%$ quartile, $\mathbf{\square}$ ) creatine phosphokinase (CPK) concentration (IU/L) by day capture and sampling (days held) ( $n$ $=48$ ). 


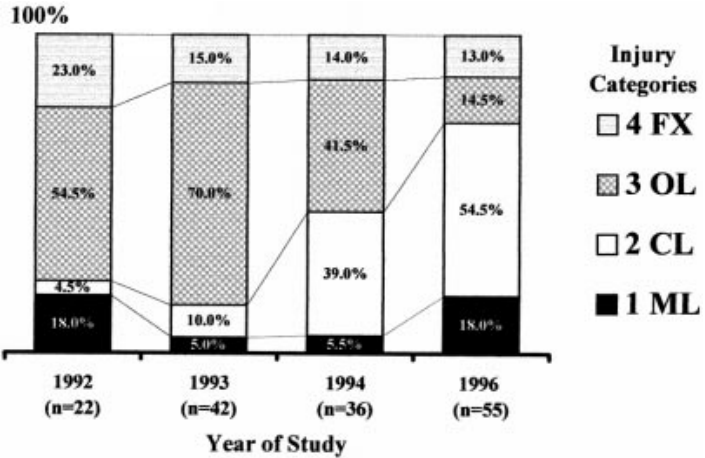

Figure 2. Percentage of trapping injuries by year of the study. $\mathrm{ML}=$ minor lacerations; $\mathrm{CL}=$ closed luxation; $\mathrm{OL}=$ open (compound) luxations; $\mathrm{FX}=$ open luxation with exposure or fracture of bones.

Trap injury data were significantly different between the years of the study (Fig. 2) and between ages (Fig. 3). A significant difference in degree of injury between the genders (Fig. 4) was evident in 1996. Evaluation of hematology and biochemistry parameters considering degree of trap injury for all years showed a slight but significant increase in the median WBC $\left(12.9 \times 10^{3} / \mu 1\right)$ and absolute numbers of neutrophils $(9,794$ per $\mu l)$ in animals in the closed luxation category versus the other trap injury categories. Serum calcium levels were increased in the animals with closed luxations (9.0 $\mathrm{mg} / \mathrm{dl}$ ) but lower in animals with open luxations $(8.3 \mathrm{mg} / \mathrm{dl})$ or fractures $(8.2 \mathrm{mg} / \mathrm{dl})$.

\section{DISCUSSION}

The influence of age on the clinical pathology parameters could be analyzed only for the study year 1996 because this was the only year that adequate numbers of juvenile animals $(n=19)$ were sampled to compare with the adults. Total WBC, absolute neutrophil, and absolute monocyte numbers were significantly higher in adult versus juvenile otters. This finding did not correlate strongly with any differences in the degree of injury sustained between adult and juvenile otters. Adult leukocyte counts could have been temporarily elevated from stress related to handling, weighing, and injections. ${ }^{8}$ Interestingly, adult and juvenile RBC and Hgb didn't differ significantly, ${ }^{8}$ possibly because of the low numbers of juveniles sampled or because the juvenile otter reaches independence and near adult weight and size prior to our December-February sampling period.

Higher erythrocyte numbers have been noted in males of various species, ${ }^{8}$ but there were no significant adult sex-related differences between eryth-

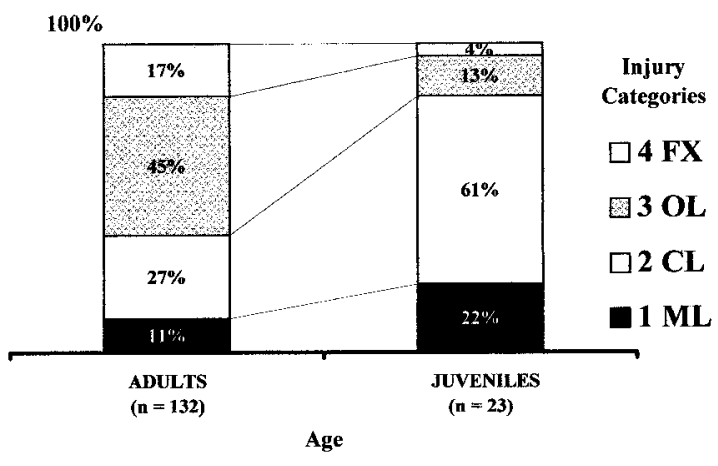

Figure 3. Percentage of trapping injuries by age group. $\mathrm{ML}=$ minor lacerations; $\mathrm{CL}=$ closed luxation; $\mathrm{OL}=$ open (compound) luxations; $\mathrm{FX}=$ open luxation with exposure or fracture of bones.

rocyte or hemoglobin values in this study, even though the trapping season coincided with postbreeding or early gestation of the river otter in North Carolina.

Analysis of the relationship of capture year to hematology parameters used results from adult male otters for all $4 \mathrm{yr}$. Significant differences in RBC and Hgb parameters appeared to be heavily impacted by the values obtained in 1993, which had greater variation in values than other years. The significant differences in $\mathrm{RBC}$ and $\mathrm{Hgb}$ could be attributed to differences in degree of injury sustained, which varied between the years and/or the use of two different hematology instruments.

Statistically significant differences were found in some of the serum biochemistry parameters. Calcium ranges were all narrow, so small differences in the two annual medians were statistically significant. The medians and ranges for alkaline phosphatase concentration also differed significantly be-

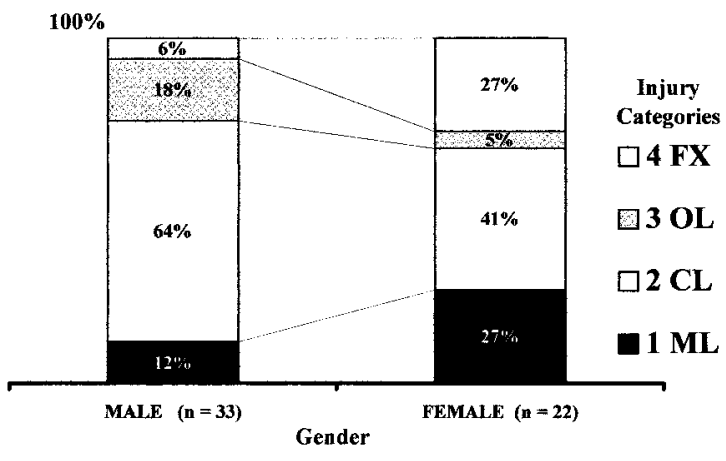

Figure 4. Percentage of trapping injuries by gender (1996 study year). ML = minor lacerations; $\mathrm{CL}=$ closed luxation; $\mathrm{OL}=$ open (compound) luxations; $\mathrm{FX}=$ open luxation with exposure or fracture of bones. 
tween the 2 yr. Some of the large difference in serum enzyme concentrations between years may have been due to the test's sensitivity to variation in temperature, reagents, and instrumentation. These differences in calcium and alkaline phosphatase concentrations did not appear to be clinically significant.

There was no significant annual variation in the amount of time the otters were held from the time of capture to the time of sampling.

Figure 1 shows a simple regression line indicating a decreasing trend in median serum CPK concentration. Each otter was sampled only once, so individual variation in CPK concentration could not be examined. Because the otters were not sampled prior to 4 days postcapture and there were no data to estimate the amount of time the otters were held within the trap, we are unable to determine when CPK peak concentration occurred, or even the peak concentration itself. However, decreasing CPK concentrations (indicative of tissue and wound healing) and the noncorrelation of time with $\mathrm{LDH}$ and WBC concentrations lend support to the practice of holding animals for a period of time after a physical trauma to allow for physiologic stabilization prior to anesthesia.

The degree of injury sustained decreased significantly between 1992 and 1996 (Fig. 2), corresponding to improving trapper proficiency. All otters in the study healed well, without incident. The difference in the degree of adult versus juvenile injuries (Fig. 3) may have been related to different mean body weights and degree of struggling in the traps. An increase of the leukocyte counts (WBC) and absolute neutrophil numbers between closed and open luxations may have been due to the increased amount of tissue trauma. There was no other significant correlation of injury with hematology values. And with regard to serum chemistry, although serum $\mathrm{Ca}$ concentrations decreased with increased degree of injury, a mechanism for this is unknown.

Dirofilaria lutra is common in river otters in the eastern United States, $2,5,6,10$ but we were unable to identify the microfilaria species found in this study. We do not know if they affected otter health. Low numbers of circulating microfilaria easily could have been missed on direct smears. We did not detect any clinical problem associated with the presence of the microfilaria, and we cannot explain the significant differences in MCV, absolute lymphocyte numbers, $\mathrm{Na}$, and $\mathrm{Cl}$ concentrations between otters with and without microfilaria. The differences may be related to animal age; the majority of microfilaria-positive animals were adults ( 25 adults/
28 positive). There was no correlation between the presence of microfilaria and absolute eosinophil count.

North Carolina river otter translocation success is due in part to the relocation of individuals determined to be clinically healthy by physical examination and evaluation of clinical pathology parameters. The baseline parameters established in this study helped evaluate the health of otters intended for translocation and can be used as guidelines for future relocation projects. Differences in season, habitat, diet, life style, and medical care may affect the values of other populations.

Acknowledgments: This study was funded in part by the North Carolina Zoological Park; the North Carolina Furbearers Association; and the College of Veterinary Medicine, North Carolina State University Environmental Medicine Consortium. We thank the Hanes Veterinary Medical Center Staff of the North Carolina Zoological Park for technical assistance and the North Carolina State University veterinary student volunteers for assistance in specimen collection.

\section{LITERATURE CITED}

1. Costa, D. P., and C. L. Ortiz. 1982. Blood chemistry homeostasis during prolonged fasting in the elephant seal. Am. J. Physiol. 242: R591-R595.

2. Davis, H. G., R. J. Aulerich, S. J. Bursian, J. G. Sikarskie, and J. N. Stuht. 1992. Hematologic and blood chemistry values of the northern river otter (Lutra canadensis). Scientifur 16: 267-271.

3. Glantz, S. A. 1992. Primer of Biostatistics, 3rd ed. McGraw-Hill, Inc., New York, New York.

4. Griffith, B., J. M. Scott, J. W. Carpenter, and C. Reed. 1993. Animal translocations and potential disease transmission. J. Zoo Wildl. Med. 24: 231-236.

5. Hoover, J. P., R. J. Baher, M. A. Nieves, R. T. Doyle, M. A. Zimmer, and S. E. Lauzon. 1985. Clinical evaluation and prerelease management of American river otters in the second year of a reintroduction study. J. Am. Vet. Med. Assoc. 187: 1154-1161.

6. Hoover, J. P., C. R. Root, and M. A. Zimmer. 1984. Clinical evaluation of American river otters in a reintroduction study. J. Am. Vet. Med. Assoc. 185: 1321-1326.

7. Hoover, J. P., and R. D. Tyler. 1986. Renal function and fractional clearances of American river otters (Lutra canadensis). J. Wildl. Dis. 22: 547-556.

8. Jain, N. C. 1993. Essentials of Veterinary Hematology. Lea and Febiger, Philadelphia, Pennsylvania.

9. Kane, K. K. 1979. Medical management of the otter. Proc. Am. Assoc. Zoo Vet. 1979: 100-103c.

10. Orihel, T. C. 1965. Dirofilaria lutrae sp. n. (Nematoda: Filarioidea) from otters in the southeast United States. J. Parasitol. 51: 409-413.

11. Rietkerk, F. E., E. C. Delima, and S. M. Mubarak. 1994. The hematological profile of the mountain gazelle 
(Gazella gazella): variation with sex, age, capture method, season, and anesthesia. J. Wildl. Dis. 30: 69-76.

12. Serfass, T. L., L. P. Randall, M. T. Whary, and R. P. Brooks. 1993. River otter (Lutra canadensis) reintroduction in Pennsylvania: prerelease care and clinical evaluation. J. Zoo Wildl. Med. 24: 28-41.

13. Spalding, M. G., and D. J. Forrester. 1993. Disease monitoring of free-ranging and released wildlife. J. Zoo Wildl. Med. 24: 271-280.

14. Spelman, L. H., W. J. Jochem, P. W. Sumner, D. P. Redmond, and M. K. Stoskopf. 1997. Postanesthetic monitoring of core body temperature using telemetry in North American river otters (Lutra canadensis). J. Zoo Wildl. Med. 28: 413-417.

15. Spelman, L. H., P. W. Sumner, W. B. Karesh, and M. K. Stoskopf. 1997. Tiletamine-zolazepam anesthesia in North American river otters (Lutra canadensis) and its partial antagonism with flumazenil. J. Zoo Wildl. Med. 28 418-423.
16. Spelman, L. H., P. W. Sumner, J. F. Levine, and M. K. Stoskopf. 1993. Field anesthesia in the North American river otter (Lutra canadensis). J. Zoo Wildl. Med. 24: 1927.

17. Spelman, L. H., P. W. Sumner, J. F. Levine, and M. K. Stoskopf. 1994. Anesthesia of North American river otters (Lutra canadensis) with medetomidine-ketamine and reversal by atipamezole. J. Zoo Wildl. Med. 25: 214 223.

18. Williams, T. D., and F. H. Kocher. 1978. Comparison of anesthetic agents in the sea otter. J. Am. Vet. Med. Assoc. 173: 1127-1130.

19. Williams, T. D., A. H. Rebar, R. F. Teclaw, and P. E. Yoos. 1992. Influence of age, sex, capture technique, and restraint on hematologic measurements and serum chemistries of wild California sea otters. Vet. Clin. Pathol. 21: 106-110.

Received for publication 27 October 1999 